\title{
Aspects of anthocyanin absorption, metabolism and pharmacokinetics in humans
}

\author{
Colin D. Kay \\ Pennsylvania State University, College of Health and Human Development, 315 Health and Human Development Building \\ East, University Park, PA 16802, USA
}

\begin{abstract}
Interest in the health-promoting properties of berry anthocyanins is intensifying; however, findings are primarily based on in vitro characteristics, leaving mechanisms associated with absorption, metabolism and pharmacokinetics largely unexplored. The present review integrates the available anthocyanin literature with that of similar flavonoids or polyphenols in order to form hypotheses regarding absorption, metabolism and clearance in humans. Of the limited available literature regarding the absorption and clearance kinetics of anthocyanins, maximum plasma concentrations are reported anywhere between 1.4 and $592 \mathrm{nmol} / 1$ and occur at $0.5-4 \mathrm{~h}$ postconsumption (doses; $68-1300 \mathrm{mg}$ ). Average urinary excretion is reported between 0.03 and $4 \%$ of the ingested dose, having elimination half-lives of $1.5-3 \mathrm{~h}$. In addition, much is unknown regarding the metabolism of anthocyanins. The most commonly cited conjugation reactions involved in the metabolism of other flavonoids include glucuronidation, methylation and sulfation. It is reasonable to suspect that anthocyanins are metabolised in much the same manner; however, until recently, there was little evidence to suggest that anthocyanins were metabolised to any significant extent. New evidence now suggests that anthocyanins are absorbed and transported in human serum and urine primarily as metabolites, with recent studies documenting as much as $68-80 \%$ of anthocyanins as metabolised derivatives in human urine. Further research is required to resolve mechanisms associated with the absorption, metabolism and clearance of anthocyanins in order to establish their true biological activities and health effects. The presented evidence will hopefully focus future research, refining study design and propagating a more complete understanding of anthocyanins' biological significance in humans.
\end{abstract}

Anthocyanins: Flavonoids: Pharmacokinetics: Metabolites

\section{Introduction}

Numerous studies have suggested that anthocyanins (Fig. 1) are protective against many chronic degenerative diseases (Kamei et al. 1995; Laplaud et al. 1997; Andriambeloson et al. 1998; Trevithick \& Mitton, 1999; Mazza, 2000; Parthasarathy et al. 2001). However, the health-promoting properties of anthocyanins are based primarily on in vitro evidence, with information regarding bioavailability, metabolism, and pharmacokinetics in humans remaining largely unknown. The limited available evidence seems to indicate that anthocyanins are poorly absorbed and not metabolised to the same extent as other flavonoids. It has therefore been suggested that anthocyanins' bioavailability is relatively low. Conversely, some researchers have suggested that anthocyanin metabolites may be overlooked using conventional methods of identification (Day \& Williamson, 2001; Felgines et al. 2003; Mazza et al. 2004; Kay et al. 2005; Manach et al. 2005). In fact, two recent studies identifying anthocyanin metabolites confirm that the absorption of anthocyanins has been underestimated (Felgines et al. 2003; Kay et al. 2005). Moreover, our work suggests that anthocyanins share common metabolic properties with other flavonoids, undergoing extensive glucuronidation and methylation in humans (Mazza et al. 2002; Kay et al. 2005). Even though anthocyanins are reported to be rapidly absorbed and eliminated, their absorption efficiency cannot be sufficiently estimated until the movement of all metabolites (intestinal, hepatic, and microbial) can be traced within the human body. Additionally, it must be considered that anthocyanins are absorbed and metabolised, and their metabolites either contribute to or retract from their overall bioactivities.

Anthocyanin metabolism in humans has yet to be adequately characterised partly due to the large variation in findings in the literature. This is probably the result of variations in dosages used in clinical studies. Since metabolic pathways that rely on cofactors are saturatable, large doses of

Abbreviations: $\mathrm{EHC}$, enterohepatic circulation; $\mathrm{t}_{\max }$, time to reach maximum concentration; $\mathrm{t}_{1 / 2}$, half-life of elimination.

Corresponding author: Dr Colin D. Kay, fax +1814863 7525, email cdk14@psu.edu 
<smiles>[R]C1=CC([R])=[O+]c2cc(O)cc(O)c2C=C1[R]</smiles>

\begin{tabular}{lccc}
\hline \multicolumn{1}{c}{ Aglycone } & $\mathrm{R}_{1}$ & $\mathrm{R}_{2}$ & $\mathrm{R}_{3}$ \\
\hline Delphinidin & $\mathrm{OH}$ & $\mathrm{OH}$ & $\mathrm{OH}$ \\
Cyanidin & $\mathrm{OH}$ & $\mathrm{H}$ & $\mathrm{OH}$ \\
Petunidin & $\mathrm{OCH}_{3}$ & $\mathrm{OH}$ & $\mathrm{OH}$ \\
Peonidin & $\mathrm{OCH}_{3}$ & $\mathrm{H}$ & $\mathrm{OH}$ \\
Malvidin & $\mathrm{OCH}_{3}$ & $\mathrm{OCH}_{3}$ & $\mathrm{OH}$ \\
Pelargonidin & $\mathrm{H}$ & $\mathrm{H}$ & $\mathrm{OH}$ \\
\hline
\end{tabular}

Fig. 1. Common anthocyanidin structures.

anthocyanins (pharmacological doses) will probably result in the saturation of metabolic pathways and consequently large amounts of unconjugated parent compounds will enter the circulation. Alternatively, anthocyanins fed in lower doses, more similar to the levels found in the diet, would not be expected to saturate metabolic pathways and the circulating species would most probably be largely conjugated. For this reason, studies feeding a single dose of anthocyanins or flavonoids will not establish a complete representation of their absorption, metabolism and pharmacokinetics. More advanced multiple-dosing studies are required to establish a true understanding of the metabolism of these compounds.

The use of insufficient extraction and identification procedures has further limited the progress of anthocyanin metabolism research. Insufficient extraction and identification procedures limit the quantification of metabolites, thereby underestimating the total absorption and bioactivity of anthocyanins. Evidence presented by Murkovic et al. (2000) further suggests that the analytical recovery of anthocyanins may be hindered as a result of binding with plasma proteins. As well, it has recently been observed that anthocyanin metabolites may degrade under various storage conditions (Felgines et al. 2003). All of the above factors probably contribute to the underreporting of anthocyanin absorption and metabolism in the literature. Once the complete metabolism of anthocyanins is established their true health-promoting properties can be sufficiently explored.

The present paper will review the absorption, metabolism and bioavailability of anthocyanins. Since there are limited data on the absorption, metabolism and bioavailability of anthocyanins to date, the review will consider mechanisms for the absorption and metabolism of the flavonoids quercetin and catechin, as they are structurally similar to anthocyanins (Fig. 2).

\section{Absorption}

Flavonoids are mostly present in foods as glycosides (Hollman \& Katan, 1998a). Glycosylation influences their biological properties, having the greatest effect on partitioning coefficients. This property is important in determining mechanisms of absorption, i.e. whether a compound will passively diffuse across a biological membrane and how it might partition internally within various cell phases. Aglycones are primarily hydrophobic and can passively diffuse through biological membranes. The linkage with sugars increases their water solubility and limits passive diffusion. Diffusion of a hydrophilic flavonoid glycoside across biological membranes is not likely to occur. Therefore, the absorption of an anthocyanin glycoside probably requires either a specific active transport mechanism or hydrolysis of the $\beta$-glycoside before absorption (Brown et al. 1998; Gee et al. 2000; Walgren et al. 2000; Day \& Williamson, 2001; Manach et al. 2005) (Fig. 3).<smiles></smiles>

Fig. 2. Structures of cyanidin (a), quercetin (b) and catechin (c). 


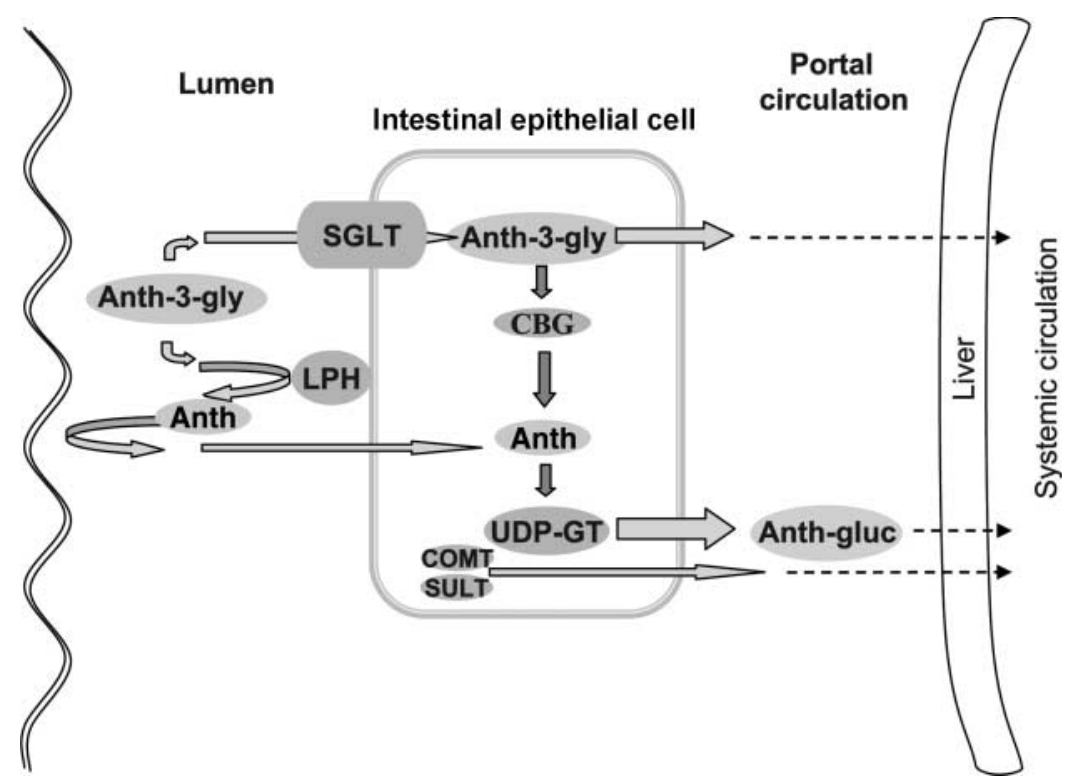

Fig. 3. Potential mechanisms of anthocyanin (Anth) absorption. SGLT, sodium-glucose co-transporter; Anth-3-gly, anthocyanin 3-glycoside; CBG, cytosolic $\beta$-glucosidase; LPH, lactate phlorizin hydrolase; UDP-GT, UDP-glucuronosyltransferase; Anth-gluc, anthocyanin glucuronide; COMT, catechol-O-methyltransferase; SULT, sulfotransferase. (Adapted from Gee et al. (2000) and Day et al. (2000).)

Human studies within the last decade have established that the absorption of most flavonoids occurs in the small intestine (Hollman et al. 1995, 1996; Scalbert \& Williamson, 2000; Williamson et al. 2000); however, the exact mechanisms involved in flavonoid absorption are a matter of much debate. It is speculated that the absorption of nonglycosylated flavonoids occurs in the small intestine via passive diffusion (Hollman et al. 1997; Donovan et al. 2001), while it has yet to be definitively established how flavonoid glycosides enter the enterocyte. The question is whether flavonoid glycosides enter the enterocyte as intact structures and are cleaved before passage across the basolateral membrane or if they are cleaved at the cell interface and move passively across the luminal membrane (Fig. 3). The two proposed mechanisms involved in the transport of flavonoid glycosides are: either the transport of the intact glucoside by a sodium-glucose co-transporter, or the extracellular hydrolysis of the glycoside via lactate phlorizin hydrolase at the brush border, followed by passive diffusion of the aglycone (Hollman et al. 1999; Gee et al. 2000; Williamson et al. 2000; Manach et al. 2005). In addition, a fraction of flavonoids will escape absorption in the upper small intestine and undergo bacterial metabolism in the lower intestine where the compounds will be deglycosylated and the aglycones will be subjected to transport or further metabolism (Scalbert \& Williamson, 2000; Williamson et al. 2000; Manach et al. 2005).

The mechanisms involved in the absorption and metabolism of anthocyanins are probably similar to those of other hydrophilic flavonoid glycosides, and may occur by one or both of the above suggested routes (Fig. 3). First, anthocyanin glycosides may be hydrolysed at the mucosal brush-border membrane by lactate phlorizin hydrolase (Gee et al. 2000; Williamson et al. 2000). Once at the brush border, the aglycone may diffuse into the enterocyte where it could either enter the portal circulation as an aglycone, or be conjugated before transference across the basolateral membrane into the serosal fluid (Laitinen \& Watkins, 1986; Hollman, 2001). Currently there is little direct evidence of anthocyanin aglycones existing in the circulation or urine of humans (Felgines et al. 2003). Also, if anthocyanin glycosides are hydrolysed at the mucosal brush-border membrane by lactate phlorizin hydrolase before absorption and conjugation with glucuronic acid, one would not expect to find parent anthocyanin glycosides in biological fluids (Table 1). Therefore a second pathway must exist, as many investigators have identified anthocyanin glycosides in human blood and urine (Table 1).

The second possible route of absorption is likely to occur via transport of the intact anthocyanin glycoside into the enterocyte, possibly by sodium-glucose co-transporter, as suggested for other flavonoids (Hollman et al. 1995; Wolffram et al. 1995; Hollman \& Katan, 1998a; Williamson et al. 2000; Mülleder et al. 2002). Supplementation of anthocyanins with various sugars has been observed to reduce the excretion of anthocyanins (Mülleder et al. 2002), suggesting the potential role of sodium-glucose cotransporter in the transport of anthocyanin glycosides. Once inside the cell, the intact glycoside could either directly cross the basolateral membrane into the portal circulation, or be hydrolysed by cytosolic $\beta$-glucosidase (Day et al. 1998; Walle et al. 2000; Williamson et al. 2000; Mülleder et al. 2002) before intestinal metabolism and transport (Hollman, 2001). Saturation of the above detailed pathways could account for the large variation in findings presented in the literature. The theory of a saturatable transport mechanism involving an Na-dependent transporter has been previously proposed for the absorption of quercetin glycosides (Mizuma et al. 1994; Hollman et al. 1995; Wolffram et al. 1995; Hollman \& Katan, 1998a). Even 


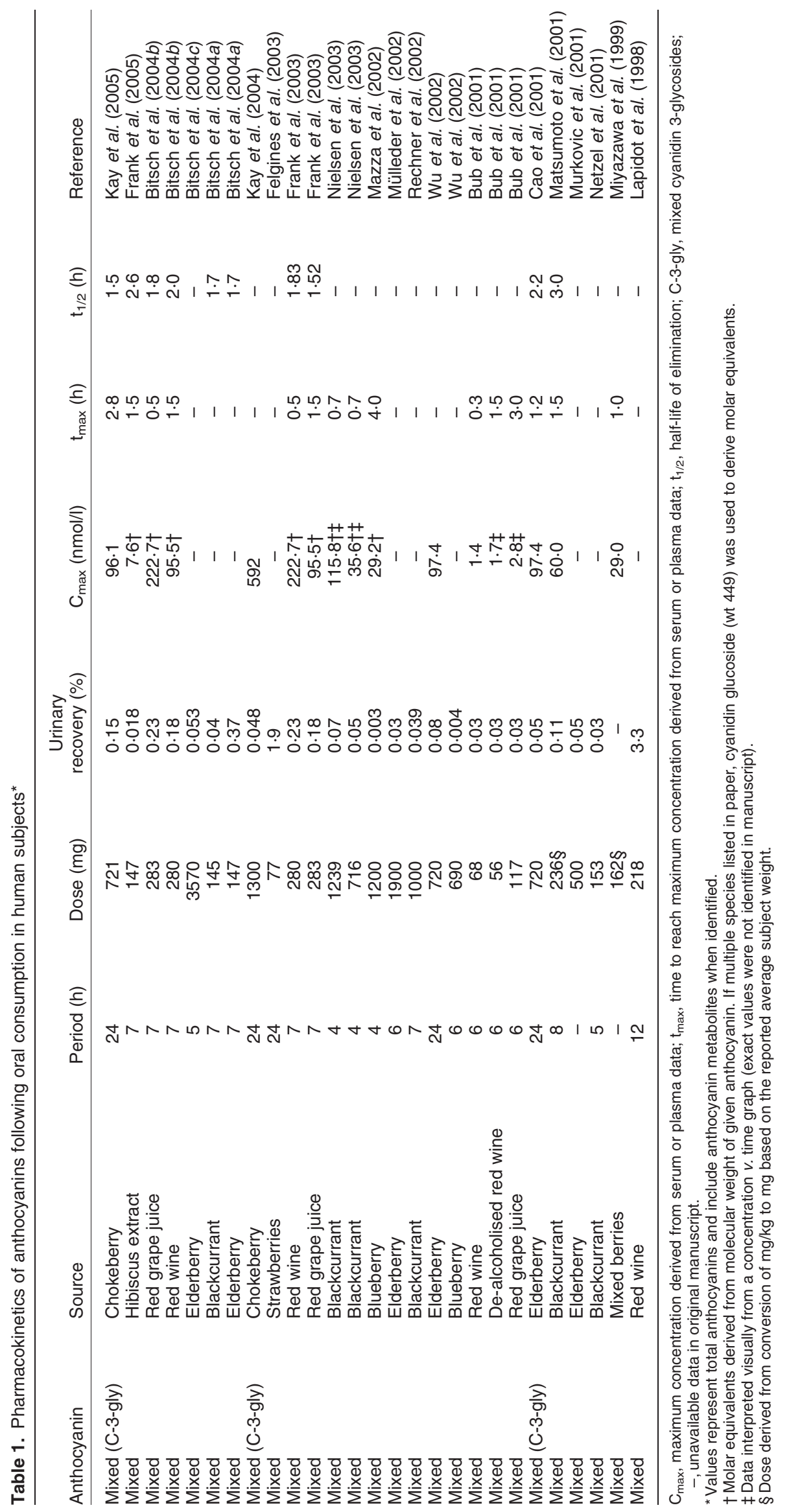


though evidence presented by Nèmeth et al. (2003) suggests that cyanidin and delphinidin glucosides are not substrates for lactate phlorizin hydrolase and cytosolic $\beta$-glucosidase, the fact remains that cyanidin glycosides are absorbed and appear as parent glycosides as well as glucuronide derivatives in the circulation (Mazza et al. 2002; Wu et al. 2002; Felgines et al. 2003; Galvano et al. 2004; Kay et al. 2004, 2005), suggesting both transport of intact compounds and hydrolysis before transport are possible. As both anthocyanin glycosides and glucuronide derivatives have been identified in human plasma and serum the current evidence suggests that both pathways are involved in the absorption of anthocyanins. It is clear that much further research is needed to resolve the mechanisms of anthocyanin absorption. The stomach has also been proposed as a site of absorption of anthocyanins (Passamonti et al. 2003; Talavéra et al. 2003); however, direct evidence of this occurring in humans has not been presented and requires further investigation.

\section{Metabolism}

Many flavonoids are extensively metabolised in humans with less than 5-10\% of the ingested parent (intact) compounds (following a low to moderate oral dose) excreted in the urine (Bravo et al. 1994). It has been reported that as much as $52 \%$ of an oral dose of radiolabelled quercetin was exhaled as ${ }^{14} \mathrm{CO}_{2}$ (Walle et al. 2001) in humans, indicating that significant absorption and extensive metabolism had occurred. Even though many flavonoids are reported to have low bioavailabilities as a result of their extensive metabolism, their metabolites may persist in the circulation for long periods of time and consequently have significant bioactivity. This was observed for quercetin, as its glucuronidated metabolites retained much of their antioxidant capacity (Morand et al. 1998). This may also be the case for anthocyanins, as metabolites identified by our group (Mazza et al. 2002; Kay et al. 2005) and Felgines et al. (2003) were reported to retain their basic anthocyanidin structures, therefore probably preserving much of their bioactivities. In order to form a working hypothesis of the metabolic fate(s) that anthocyanins may have in the body, it is necessary to first review the basic processes associated with flavonoid and polyphenol metabolism.

Research conducted within the last decade suggests that the majority of flavonoids are found in the circulation and urine as methylated, sulfated, glucuronidated and glycated conjugates (Aziz et al. 1998; Hollman \& Katan, 1998a,b; Shimoi et al. 1998; Donovan et al. 2001; Manach et al. 2005), with only $0 \cdot 1-1.5 \%$ of ingested dietary quercetin reported to be excreted unmetabolised (Balant et al. 1979; Hollman et al. 1995, 1997, 1999; Aziz et al. 1998). Glucuronide conjugation is regarded as the major conjugation reaction involved in flavonoid metabolism (Shimoi et al. 1998; Spencer et al. 1999; Kuhnle et al. 2000; Donovan et al. 2001; Oliveira et al. 2002). There are two main reasons for the widespread utilisation of the glucuronidation pathway: first, glucuronic acid is derived directly from glucose, and its store, glycogen, and is therefore readily available; second, glucuronic acid has the capacity to be conjugated with a wide range of compounds. O-glucuronides (linkage through an oxygen atom) are the most common form of glucuronide conjugation (Dutton, 1980), making the highly hydroxylated flavonoids prime targets for glucuronidation. The glucuronidation reaction is catalysed by UDP-glucuronosyltranferases which is found in high concentrations in the liver, intestine and kidneys. Of all the tissues, the liver has the greatest capacity for glucuronidation (Mojarrabi \& Mackenzie, 1998; Strassburg et al. 1998), although more and more evidence points toward the intestine as being the initial and principal site for flavonoid glucuronidation in humans following typical dietary consumption (Cheng et al. 1999; Crespy et al. 1999; Donovan et al. 2001).

Methylation appears to be the second most significant conjugation reaction involving flavonoids (Kuhnle et al. 2000; Williamson et al. 2000). Methylation is driven by a group of enzymes referred to as methyltransferases. These non-specific enzymes are found in many tissues including the liver and intestine (Laitinen \& Watkins, 1986). The most common methylation reaction associated with flavonoid metabolism is O-methylation. O-methylation is catalysed by catechol-O-methyltransferase utilising S-adenosyl methionine as a cofactor. The liver has the highest catecholO-methyltransferase activity and is the main organ responsible for methylation (Piskula \& Terao, 1998). The hydroxylation pattern of a flavonoid's ring structure will determine the primary site of methylation. Studies reveal that quercetin is extensively methylated following low oral doses in humans and in animals (Manach et al. 1998; Williamson et al. 2000).

Sulfation or glycination are also common conjugation reactions which predominate when low doses of phenolic drugs are administered. Sulfation reactions are catalysed by sulfotransferases, which are a small group of cytosolic enzymes widely distributed throughout the body. They utilise phosphoadenosine- $5^{\prime}$-phosphosulfate as a cofactor and their known substrates include phenols and polyphenols (i.e. flavonoids), iodothyronines, 4-nitrophenol, and hydroxyarylamines (Dutton, 1980; Coughtrie et al. 1998). Additionally, sulfation, as a conjugation reaction, is relatively costly in ATP and sulfate and is more likely to be rapidly limited by aglycone loading than is glucuronidation (Dutton, 1980). Therefore, sulfate conjugation is regarded as a highly saturatable pathway, making it difficult to identify flavonoid sulfides as a result of their relatively low concentrations in the blood and urine.

The body of knowledge regarding the subject of anthocyanin metabolism is much less extensive than that of many other flavonoids, with the metabolic consequence(s) of anthocyanins still a matter of much debate (Fig. 4; potential pathways in the body). The presence of unmetabolised (parent) anthocyanin glycosides in human blood and urine has been extensively documented (Table 1). However, even though many investigators suggest that anthocyanins are not metabolised before release into the systemic circulation, recent evidence indicates otherwise. The detection of glucuronide (Wu et al. 2002; Felgines et al. 2003; Kay et al. 2004, 2005), methyl (Wu et al. 2002; Kay et al. 2004, 2005) and sulfoconjugates (Felgines et al. 2003) has recently been documented, with investigations reporting 


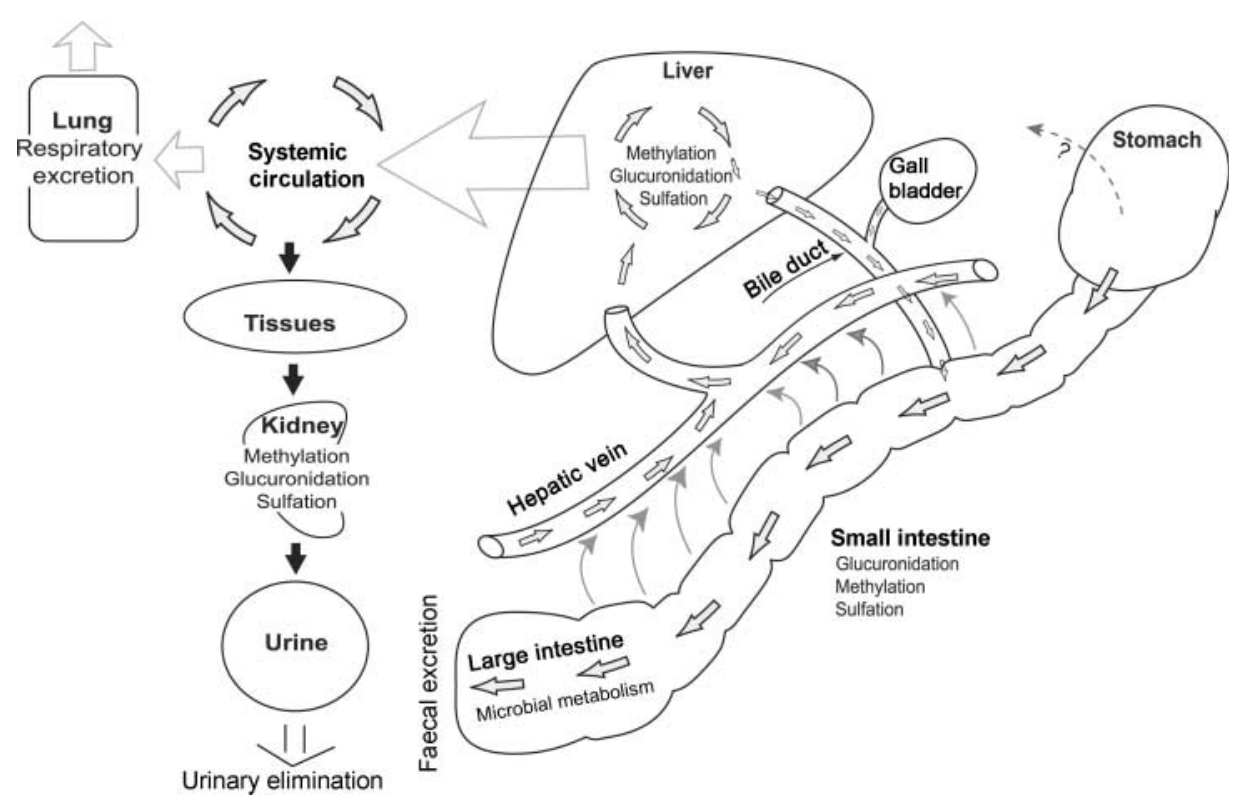

Fig. 4. Potential route for anthocyanin absorption, metabolism and elimination.

between $68 \%$ (Kay et al. 2005) and $80 \%$ (Felgines et al. 2003) of anthocyanins in the urine as metabolised derivatives. Studies identifying anthocyanins exclusively as unmetabolised parent compounds probably result from either saturation of metabolic pathways following megadose interventions, insufficient extraction procedures, and misidentification as a result of insufficient detection methods (i.e. using UV-visible HPLC exclusively for identification).

\section{Elimination and reabsorption}

The route of elimination of anthocyanins and flavonoids (Fig. 4) will ultimately depend on the type of conjugates produced and their site of production. Glucuronides formed in the intestine tend to enter the systemic circulation directly and are not readily available for biliary excretion unlike those newly formed in the liver, which are predominantly excreted into the bile. This implies that glucuronidation in the intestinal cells facilitates the loss of flavonoids from enterohepatic circulation (EHC) towards the systemic circulation. Compounds undergoing EHC may also undergo further sulfation in the intestine or hepatocyte, which would divert them from biliary excretion toward eventual urinary elimination, as enteral reabsorption of strongly polar compounds is negligible (Gregus \& Klassen, 1986).

EHC prolongs the residence of a chemical or xenobiotic in the body by reducing its faecal excretion. If a compound undergoing EHC is also available to the systemic circulation, this will result in a longer plasma elimination half-life $\left(\mathrm{t}_{1 / 2}\right.$; Gregus \& Klassen, 1986). EHC is likely to be a major factor in the metabolism of many flavonoids and is responsible for their low but consistent levels in the circulation long after their time to reach maximum concentration $\left(t_{\max }\right)$ is achieved (for example, quercetin $\mathrm{t}_{\max } 1-2 \mathrm{~h} ; \mathrm{t}_{1 / 2}$ 11-28 $\mathrm{h}$ ) (Manach et al. 2005). Although it appears that various forms of quercetin may undergo EHC, current evidence suggests that this is probably not a major route for the elimination for highly polar anthocyanin glycosides as their $t_{1 / 2}$ is reported to be relatively short $\left(t_{\max }\right.$ $1-4 \mathrm{~h} ; \mathrm{t}_{1 / 2} 1-4 \mathrm{~h}$ ) (Table 1). This, however, is only speculatory as the biliary excretion of anthocyanins in humans is currently unexplored.

The urinary excretion of most flavonoids is relatively low (for example, quercetin about $2.5 \%$ ) with the exception of the isoflavonoids (for example, genistein and daidzein about 5-50 \%) (Manach et al. 2005). Similarly the urinary excretion of anthocyanins is generally reported between 0.01 and $3 \%$ of the ingested dose (Table 1). In addition, the urinary elimination of colonic metabolites of anthocyanins is largely unknown and may be significant.

Colonic bacteria are likely to play a major role in the metabolism of anthocyanins. Many flavonoids are extensively metabolised by colonic bacteria, leaving a range of phenolic acids which may be reabsorbed (Das \& Sothy, 1971; Shaw \& Griffiths, 1980; Hackett, 1986; Hollman et al. 2001; Manach et al. 2005). Colonic bacteria cleave glycosides from their parent compounds for catabolism, leaving the resulting aglycones for reabsorption through the intestinal wall or further degradation (Boulton et al. 1999; Schneider et al. 1999; Skibola \& Smith, 2000). In a study conducted by Das \& Sothy (1971) utilising radiolabelled catechin, $\left[{ }^{14} \mathrm{C}\right]$ phenolic acid metabolites were found to be reabsorbed and excreted in the urine of rats post-bacterial degradation. Conversely, in a study by Schneider et al. (1999) utilising colonic bacteria isolated from human faeces, quercetin-3-glucoside was observed to be degraded to quercetin; however, the majority of quercetin aglycone was left intact. The extent to which flavonoids are eliminated in the faeces of humans is undetermined for many flavonoids including anthocyanins.

Tsuda et al. (1999) reported a significant increase in plasma concentrations of protocatechuic acid following the administration of cyanidin glycosides to rats. The 
researchers suggested that the protocatechuic acid may be derived from the breakdown of anthocyanins. The concentration of protocatechuic acid in the plasma was reported to be eight-fold higher than the parent anthocyanins. Additionally a recent in vitro fermentation study has confirmed that protocatechuic acid is a major metabolic byproduct of anthocyanins by human faecal bacteria (Aura et al. 2004). Radiolabelling studies are required to establish the extent to which this occurs in humans in vivo. If anthocyanins are readily absorbed and less than $2 \%$ are generally identified in the urine, it is possible that a significant proportion of anthocyanins exist as colonic metabolites in the circulation. Additionally, if a large conversion of anthocyanins to phenolic acids and phenolic acid residues does occur, these compounds would not be easily identified in biological fluids using traditional HPLC techniques and would probably go undetected.

Varying proportions of flavonoids present in food will also pass through the gastrointestinal tract unabsorbed and be eliminated in the faeces (Rozman, 1986). Studies feeding oral doses of radiolabelled quercetin (Ueno et al. 1983) and catechin (Matsumoto et al. 2001) to rats reported 30-32\% of the radiolabelled compounds to be excreted in the faeces unmetabolised. Empirical evidence for the excretion of anthocyanins in human faeces is currently not available.

The lung is responsible for the elimination of volatile substances from the body and is a major site of excretion for many xenobiotics. In a study by Petrakis et al. (1959), $44 \%$ of the radioactivity of ${ }^{14} \mathrm{C}$-labelled quercetin was detected in the gastrointestinal tract of rats and $11 \%$ was detected in the lungs. More recently, it has been reported that as much as $52 \%$ of an oral dose of radiolabelled quercetin in humans was exhaled as ${ }^{14} \mathrm{CO}_{2}$ (Walle et al. 2001). Unfortunately, the relative respiratory excretion of many flavonoids, including anthocyanins, is still unknown.

\section{Pharmacokinetics}

The pharmacokinetics of flavonols, flavanones, flavanols and isoflavones has been extensively studied and reviewed elsewhere (Hollman \& Katan, 1999; Ross \& Kasum, 2002; Scalbert et al. 2002; Karakaya, 2004; Manach \& Donovan, 2004; Walle, 2004; Manach et al. 2005; Williamson \& Manach, 2005). Complete pharmacokinetic data regarding anthocyanins are limited. The available data suggest that maximum plasma concentrations of anthocyanins in humans are generally between 1.4 and $592 \mathrm{nmol} / \mathrm{l}$, and are reported to occur between $0 \cdot 5-4 \mathrm{~h}$ post-consumption of doses ranging between 68 and $1300 \mathrm{mg}$. Additionally, the average urinary excretion of parent glycosides is generally reported between 0.03 and $4 \%$ of the ingested dose, with a maximum rate of urinary excretion occurring between 1 and $4 \mathrm{~h}$ and having a $\mathrm{t}_{1 / 2}$ of $1.5-3 \mathrm{~h}$ (Table 1 ). Even though the reported elimination rates for quercetin are slow $\left(\mathrm{t}_{1 / 2} 11-28 \mathrm{~h}\right)$, suggesting the possibility for bioaccumulation (Manach et al. $2005)$, the elimination of anthocyanins is quite rapid $\left(t_{1 / 2}\right.$ $1.5-3 \mathrm{~h}$ ) and accumulation is not likely to occur to any significant extent following normal dietary consumption. However, the significance of the accumulation of colonic metabolites and aglycone breakdown products has yet to be explored.

\section{Summary and conclusion}

The literature suggests that anthocyanins may have important health effects; however, from the present review, it is quite apparent that basic aspects of their absorption and metabolism are not fully established. Complete metabolic studies involving compound labelling and the collection of blood, urine, $\mathrm{CO}_{2}$ and faeces are required. Furthermore, multi-dose interventions are necessary to determine the complete pharmacokinetic profiles of all major anthocyanins and anthocyanin metabolites. The limited available data as presented suggest that anthocyanins are absorbed and transported in human serum and urine primarily as metabolites. The contribution of each individual metabolite to the reported biological activity of anthocyanins should be a focus of future research. Once the complete metabolism of anthocyanins is established their true biological activities and heath effects can be explored.

\section{Acknowledgements}

The present study is supported by a Natural Sciences and Engineering Research Council of Canada (NSERC) postdoctoral fellowship.

\section{References}

Andriambeloson E, Magnier C, Haan-Archipoff G, Lobstein A, Anton R, Beretz A, Stoclet JC \& Andriantsitohaina R (1998) Natural dietary polyphenolic compounds cause endotheliumdependent vasorelaxation in rat thoracic aorta. Journal of Nutrition 128, 2324-2333.

Aura AM, Martin-Lopez P, O'Leary KA, Williamson G, OksmanCaldentey KM, Poutanen K \& Santos-Buelga C (2004) In vitro metabolism of anthocyanins by human gut microflora. European Journal of Nutrition 28, 1-10.

Aziz AA, Edwards CA, Lean ME \& Crozier A (1998) Absorption and excretion of conjugated flavonols, including quercetin-4'-Obeta-glucoside and isorhamnetin-4'-O-beta-glucoside by human volunteers after the consumption of onions. Free Radical Research 29, 257-269.

Balant L, Burki B, Wermeille M \& Golden G (1979) Comparison of some pharmacokinetic parameters of $(+)$-cyanidanol-3 obtained with specific and non-specific analytical methods. Arzneimittelforschung 29, 1758-1762.

Bitsch I, Janssen M, Netzel M, Strass G \& Frank T (2004a) Bioavailability of anthocyanidin-3-glycosides following consumption of elderberry extract and blackcurrant juice. International Journal of Clinincal Pharmacology and Therapeutics 42, 293-300.

Bitsch R, Netzel M, Frank T, Strass G \& Bitsch I (2004b) Bioavailability and biokinetics of anthocyanins from red grape juice and red wine. Journal of Biomedicine and Biotechnology 5, 293-298.

Bitsch R, Netzel M, Sonntag S, Strass G, Frank T \& Bitsch I (2004c) Urinary excretion of cyanidin glucosides and glucuronides in healthy humans after elderberry juice ingestion. Journal of Biomedicine and Biotechnology 5, 343-345.

Boulton DW, Walle UK \& Walle T (1999) Fate of the flavonoid quercetin in human cell lines: chemical instability and metabolism. Journal of Pharmacy and Pharmacology 51, 353-359.

Bravo L, Abia R, Eastwood MA \& Saura-Calixto F (1994) Degradation of polyphenols (catechin and tannic acid) in the rat 
intestinal tract. Effect on colonic fermentation and faecal output. British Journal of Nutrition 71, 933-946.

Brown JE, Khodr H, Hider RC \& Rice-Evans CA (1998) Structural dependence of flavonoid interactions with $\mathrm{Cu}^{2+}$ ions: implications for their antioxidant properties. Biochemistry Journal 330, 1173-1178.

Bub A, Watzl B, Heeb D, Rechkemmer G \& Briviba K (2001) Malvidin-3-glucoside bioavailability in humans after ingestion of red wine, dealcoholized red wine and red grape juice. European Journal of Nutrition 40, 113-120.

Cao G, Muccitelli HU, Sanchez-Moreno C \& Prior RL (2001) Anthocyanins are absorbed in glycated forms in elderly women: a pharmacokinetic study. American Journal of Clinical Nutrition 73, 920-926.

Cheng Z, Radominska-Pandya A \& Tephly TR (1999) Studies on the substrate specificity of human intestinal UDP-lucuronosyltransferases 1A8 and 1A10. Drug Metabolism and Disposition 27, 1165-1170.

Coughtrie MH, Sharp S, Maxwell K \& Innes NP (1998) Biology and function of the reversible sulfation pathway catalysed by human sulfotransferases and sulfatases. Chemico-biological Interactions 109, 3-27.

Crespy V, Morand C, Manach C, Besson C, Demigne C \& Remesy C (1999) Part of quercetin absorbed in the small intestine is conjugated and further secreted in the intestinal lumen. American Journal of Physiology 277, G120-G126.

Das NP \& Sothy SP (1971) Studies on flavonoid metabolism. Biliary and urinary excretion of metabolites of $(+)-(\mathrm{U}-14 \mathrm{C})$ catechin. Biochemistry Journal 125, 417-423.

Day AJ, Canada FJ, Diaz JC, Kroon PA, Mclauchlan R, Faulds CB, Plumb GW, Morgan MR \& Williamson G (2000) Dietary flavonoid and isoflavone glycosides are hydrolysed by the lactase site of lactase phlorizin hydrolase. FEBS Letters 468, $166-170$.

Day AJ, DuPont MS, Ridley S, Rhodes M, Rhodes MJ, Morgan MR \& Williamson G (1998) Deglycosylation of flavonoid and isoflavonoid glycosides by human small intestine and liver betaglucosidase activity. FEBS Letters 436, 71-75.

Day AJ \& Williamson G (2001) Biomarkers for exposure to dietary flavonoids: a review of the current evidence for identification of quercetin glycosides in plasma. British Journal of Nutrition 86, S105-S110.

Donovan JL, Crespy V, Manach C, Morand C, Besson C, Scalbert A \& Remesy C (2001) Catechin is metabolized by both the small intestine and liver of rats. Journal of Nutrition 131, 1753-1757.

Dutton GJ (1980) Glucuronidation of Drugs and other Compounds. Boca Raton, FL: CRC Press.

Felgines C, Talavera S, Gonthier MP, Texier O, Scalbert A, Lamaison JL \& Remesy C (2003) Strawberry anthocyanins are recovered in urine as glucuro- and sulfoconjugates in humans. Journal of Nutrition 133, 1296-1301.

Frank T, Janssen M, Netzel M, Strass G, Kler A, Kriesl E \& Bitsch I (2005) Pharmacokinetics of anthocyanidin-3-glycosides following consumption of Hibiscus sabdariffa L. extract. Journal of Clinical Pharmacology 45, 203-210.

Frank T, Netzel M, Strass G, Bitsch R \& Bitsch I (2003) Bioavailability of anthocyanidin-3-glucosides following consumption of red wine and red grape juice. Canadian Journal of Physiology and Pharmacology 81, 423-435.

Galvano F, La Fauci L, Lazzarino G, Fogliano V, Ritieni A, Ciappellano S, Battistini NC, Tavazzi B \& Galvano G (2004) Cyanidins: metabolism and biological properties. Journal of Nutritional Biochemistry 15, 2-11.

Gee JM, DuPont MS, Day AJ, Plumb GW, Williamson G \& Johnson IT (2000) Intestinal transport of quercetin glycosides in rats involves both deglycosylation and interaction with the hexose transport pathway. Journal of Nutrition 130, 2765-2771.
Gregus Z \& Klassen CD (1986) Enterohepatic circulation of toxicants. In Gastrointestinal Toxicology, pp. 57-99 [K Rozman and O Hänninen, editors]. New York: Elsevier.

Hackett AM (1986) The metabolism of flavonoid compounds in mammals. In Plant Flavonoids in Biology and Medicine, pp. 177-194 [V Cody, E Middleton and JB Harborne, editors]. New York: Alan R Liss Inc.

Hollman PC, Bijsman MN, van Gameren Y, Cnossen EP, de Vries JH \& Katan MB (1999) The sugar moiety is a major determinant of the absorption of dietary flavonoid glycosides in man. Free Radical Research 31, 569-573.

Hollman PC, de Vries JH, van Leeuwen SD, Mengelers MJ \& Katan MB (1995) Absorption of dietary quercetin glycosides and quercetin in healthy ileostomy volunteers. American Journal of Clinical Nutrition 62, 1276-1282.

Hollman PC \& Katan MB (1998a) Bioavailability and health effects of dietary flavonols in man. Archives of Toxicology Supplement 20, 237-248.

Hollman PC \& Katan MB (1998b) Absorption, metabolism and bioavailability of flavonoids. In Flavonoids in Health and Disease, pp. 483-522 [CA Rice-Evans and L Packer, editors]. New York: Marcel Dekker, Inc.

Hollman PC \& Katan MB (1999) Health effects and bioavailability of dietary flavonols. Free Radical Research 31, S75-S80.

Hollman PC, van der Gaag M, Mengelers MJ, van Trijp JM, de Vries JH \& Katan MB (1996) Absorption and disposition kinetics of the dietary antioxidant quercetin in man. Free Radical Biology and Medicine 21, 703-707.

Hollman PC, van Trijp JM, Buysman MN, van der Gaag MS, Mengelers MJ, de Vries JH \& Katan MB (1997) Relative bioavailability of the antioxidant flavonoid quercetin from various foods in man. FEBS Letters 418, 152-156.

Hollman PCH (2001) Evidence for health benefits of plant phenols: local or systemic effects? Journal of the Science of Food and Agriculture 81, 842-852.

Kamei H, Kojima T, Hasegawa M, Koide T, Umeda T, Yukawa T \& Terabe K (1995) Suppression of tumor cell growth by anthocyanins in vitro. Cancer Investigation 13, 590-594.

Karakaya S (2004) Bioavailability of phenolic compounds. Critical Reviews in Food Science and Nutrition 44, 453-464.

Kay CD, Mazza G \& Holub BJ (2005) Anthocyanins exist in the circulation primarily as metabolites in adult men. Journal of Nutrition 135, 2582-2588.

Kay CD, Mazza G, Holub BJ \& Wang J (2004) Anthocyanin metabolites in human urine and serum. British Journal of Nutrition 91, 933-942.

Kuhnle G, Spencer JP, Schroeter H, Shenoy B, Debnam ES, Srai SK, Rice-Evans C \& Hahn U (2000) Epicatechin and catechin are O-methylated and glucuronidated in the small intestine. Biochemical and Biophysical Research Communications 277, 507-512.

Laitinen M \& Watkins JB (1986) Mucosal biotransformations. In Gastrointestinal Toxicology, pp. 169-192 [K Rozman and O Hänninen, editors]. New York: Elsevier.

Lapidot T, Harel S, Granit R \& Kanner J (1998) Bioavailiblity of red wine anthocyanins as detected in human urine. Journal of Agricultural and Food Chemistry 46, 4297-4302.

Laplaud PM, Lelubre A \& Chapman MJ (1997) Antioxidant action of Vaccinium myrtillus extract on human low density lipoproteins in vitro: initial observations. Fundamental and Clinical Pharmacology 11, 35-40.

Manach C \& Donovan JL (2004) Pharmacokinetics and metabolism of dietary flavonoids in humans. Free Radical Research 38, 771-785.

Manach C, Morand C, Crespy V, Demigne C, Texier O, Regerat F \& Remesy C (1998) Quercetin is recovered in human plasma as 
conjugated derivatives which retain antioxidant properties. FEBS Letters 426, 331-336.

Manach C, Williamson G, Morand C, Scalbert A \& Remesy C (2005) Bioavailability and bioefficacy of polyphenols in humans. I. Review of 97 bioavailability studies. American Journal of Clinical Nutrition 81, S230-S242.

Matsumoto H, Hanamura S, Kawakami T, Sato Y \& Hirayama M (2001) Preparative-scale isolation of four anthocyanin components of black currant (Ribes nigrum L.) fruits. Journal of Agricultural and Food Chemistry 49, 1541-1545.

Mazza G (2000) Health aspects of natural colors. In Natural Food Colorants: Science and Technology, pp. 289-314 [GJ Lauro and FJ Francis, editors]. New York: Marcel Dekker Inc.

Mazza G, Cacace JE \& Kay CD (2004) Methods of analysis for anthocyanins in plants and biological fluids. Journal of $A O A C$ International 87, 129-145.

Mazza G, Kay CD, Cottrell T \& Holub BJ (2002) Absorption of anthocyanins from blueberries and serum antioxidant status in human subjects. Journal of Agricultural and Food Chemistry 50, $7731-7737$.

Miyazawa T, Nakagawa K, Kudo M, Muraishi K \& Someya K (1999) Direct intestinal absorption of red fruit anthocyanins, cyanidin-3-glucoside and cyanidin-3,5-diglucoside, into rats and humans. Journal of Agricultural and Food Chemistry 47, $1083-1091$

Mizuma T, Ohta K \& Awazu S (1994) The beta-anomeric and glucose preferences of glucose transport carrier for intestinal active absorption of monosaccharide conjugates. Biochimica et Biophysica Acta 1200, 117-122.

Mojarrabi B \& Mackenzie PI (1998) Characterization of two UDP glucuronosyltransferases that are predominantly expressed in human colon. Biochemical and Biophysical Research Communications 247, 704-709.

Morand C, Crespy V, Manach C, Besson C, Demigne C \& Remesy C (1998) Plasma metabolites of quercetin and their antioxidant properties. American Journal of Physiology 275, 212-219.

Mülleder U, Murkovic M \& Pfannhauser W (2002) Urinary excretion of cyanidin glycosides. Journal of Biochemical and Biophysical Methods 53, 61-66.

Murkovic M, Adam U \& Pfannhauser W (2000) Analysis of anthocyanin glycosides in human serum. Fresenius' Journal of Analytical Chemistry 366, 379-381.

Murkovic M, Mülleder U, Adam U \& Pfannhauser W (2001) Detection of anthocyanins from elderberry juice in human urine. Journal of the Science of Food and Agriculture 81, 934-937.

Nèmeth K, Plumb GW, Berrin JG, Juge N, Jacob R, Naim HY, Williamson G, Swallow DM \& Kroon PA (2003) Deglycosylation by small intestinal epithelial cell beta-glucosidases is a critical step in the absorption and metabolism of dietary flavonoid glycosides in humans. European Journal of Nutrition 42, 29-42.

Netzel M, Strass G, Janssen M, Bitsch I \& Bitsch R (2001) Bioactive anthocyanins detected in human urine after ingestion of blackcurrant juice. Journal of Environmental Pathology, Toxicology and Oncology 20, 89-95.

Nielsen IL, Dragsted LO, Ravn-Haren G, Freese R \& Rasmussen SE (2003) Absorption and excretion of black currant anthocyanins in humans and watanabe heritable hyperlipidemic rabbits. Journal of Agriculture and Food Chemistry 51, 2813-2820

Oliveira EJ, Watson DG \& Grant MH (2002) Metabolism of quercetin and kaempferol by rat hepatocytes and the identification of flavonoid glycosides in human plasma. Xenobiotica 32, 279-287.

Parthasarathy S, Khan-Merchant N, Penumetcha M \& Santanam N (2001) Oxidative stress in cardiovascular disease. Journal of Nuclear Cardiology 8, 379-389.
Passamonti S, Vrhovsek U, Vanzo A \& Mattivi F (2003) The stomach as a site for anthocyanins absorption from food. FEBS Letters 544, 210-213.

Petrakis P, Kallianos AG, Wender SH \& Shetlar MR (1959) Metabolic studies of quercetin labelled with $\mathrm{C}^{14}$. Archives of Biochemistry and Biophysics 85, 264-271.

Piskula MK \& Terao J (1998) Accumulation of (-)-epicatechin metabolites in rat plasma after oral administration and distribution of conjugation enzymes in rat tissues. Journal of Nutrition 128, 1172-1178.

Rechner AR, Kuhnle G, Hu H, Roedig-Penman A, van den Braak MH, Moore KP \& Rice-Evans CA (2002) The metabolism of dietary polyphenols and the relevance to circulating levels of conjugated metabolites. Free Radical Research 36, 1229-1241.

Ross JA \& Kasum CM (2002) Dietary flavonoids: bioavailability, metabolic effects, and safety. Annual Review of Nutrition 22, 19-34.

Rozman K (1986) Fecal excretion of toxic substances. In Gastrointestinal Toxicology, pp. 119-145 [K Rozman and O Hänninen, editors]. New York: Elsevier.

Scalbert A, Morand C, Manach C \& Remesy C (2002) Absorption and metabolism of polyphenols in the gut and impact on health. Biomedicine and Pharmacotherapy 56, 276-282.

Scalbert A \& Williamson G (2000) Dietary intake and bioavailability of polyphenols. Journal of Nutrition 130, S2073-S2085.

Schneider H, Schwiertz A, Collins MD \& Blaut M (1999) Anaerobic transformation of quercetin-3-glucoside by bacteria from the human intestinal tract. Archives of Microbiology 171, 81-91.

Shaw IC \& Griffiths LA (1980) Identification of the major biliary metabolite of $(+)$-catechin in the rat. Xenobiotica 10, 905-911.

Shimoi K, Okada H, Furugori M, Goda T, Takase S, Suzuki M, Hara Y, Yamamoto H \& Kinae N (1998) Intestinal absorption of luteolin and luteolin 7-O-beta-glucoside in rats and humans. FEBS Letters 438, 220-224.

Skibola CF \& Smith MT (2000) Potential health impacts of excessive flavonoid intake. Free Radical Biology and Medicine 29, 375-383.

Spencer JP, Chowrimootoo G, Choudhury R, Debnam ES, Srai SK \& Rice-Evans C (1999) The small intestine can both absorb and glucuronidate luminal flavonoids. FEBS Letters 458, 224-230.

Strassburg CP, Nguyen N, Manns MP \& Tukey RH (1998) Polymorphic expression of the UDP-glucuronosyltransferase UGT1A gene locus in human gastric epithelium. Molecular Pharmacology 54, 647-654.

Talavéra S, Felgines C, Texier O, Besson C, Lamaison J \& Rémésy C (2003) Anthocyanins are efficiently absorbed from the stomach in anesthetized rats. Journal of Nutrition 133, 4178-4182.

Trevithick JR \& Mitton KP (1999) Antioxidants and diseases of the eye. In Antioxidant Status, Diet, Nutrition, and Health, pp. 545-566 [AM Papas, editor]. Boca Raton, FL: CRC Press.

Tsuda T, Horio F \& Osawa T (1999) Absorption and metabolism of cyanidin 3-O-beta-D-glucoside in rats. FEBS Letters 449, $179-182$.

Ueno I, Nakano N \& Hirono I (1983) Metabolic fate of quercetin in the ACI rat. Japanese Journal of Experimental Medicine 53, 41-50.

Walgren RA, Karnaky KJ Jr, Lindenmayer GE \& Walle T (2000) Efflux of dietary flavonoid quercetin 4'-beta-glucoside across human intestinal Caco-2 cell monolayers by apical multidrug resistance-associated protein-2. Journal of Pharmacology and Experimental Therapeutics 294, 830-836.

Walle T (2004) Absorption and metabolism of flavonoids. Free Radical Biology and Medicine 36, 829-837. 
Walle T, Otake Y, Walle UK \& Wilson FA (2000) Quercetin glucosides are completely hydrolyzed in ileostomy patients before absorption. Journal of Nutrition 30, 2658-2661.

Walle T, Walle UK \& Halushka PV (2001) Carbon dioxide is the major metabolite of quercetin in humans. Journal of Nutrition 131, 2648-2652.

Williamson G, Day AJ, Plumb GW \& Couteau D (2000) Human metabolic pathways of dietary flavonoids and cinnamates. Biochemical Society Transaction 28, 16-22.
Williamson G \& Manach C (2005) Bioavailability and bioefficacy of polyphenols in humans. II. Review of 93 intervention studies. American Journal of Clinical Nutrition 81, S243-S255.

Wolffram S, Weber T, Grenacher B \& Scharrer EA (1995) Na(+)dependent mechanism is involved in mucosal uptake of cinnamic acid across the jejunal brush border in rats. Journal of Nutrition 125, 1300-1308.

Wu X, Cao G \& Prior RL (2002) Absorption and metabolism of anthocyanins in elderly women after consumption of elderberry or blueberry. Journal of Nutrition 132, 1865-1871. 